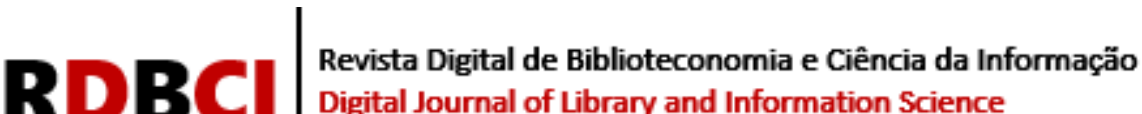

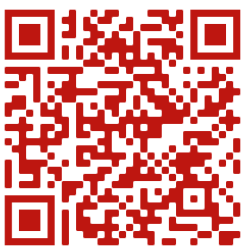

EDITORIAL ${ }^{1}$

\section{Tópicos e diversidade temática em Biblioteconomia e Ciência da Informação}

\author{
Gildenir Carolino Santos ${ }^{1}$ iD https://orcid.org/0000-0002-4375-6815 \\ ${ }^{1}$ Universidade Estadual de Campinas, Campinas, SP, Brasil / e-mail: gilldenir@unicamp.br
}

O novo cenário que estamos vivenciando tem nos chamado a repensar o papel da editoração científica como suporte educacional à universidade, pois, em uma sociedade organizada em torno das Tecnologias digitais e informacionais e comunicacionais, nunca esteve tão presentes neste momento de pandemia para que ela possa aprimorar e desenvolver recursos informacionais online das publicações para atender as necessidades editoriais da comunidade usuária interna e externa, visto que as bibliotecas universitárias estão cumprindo esse papel na sociedade conectada, pois são fundamentais para a produção do conhecimento científico.

Desse novo panorama, damos início a este editorial comemorando e celebrando mais uma edição concluída da RDBCI como publicação contínua em 2020, vinculada ao Sistema de Bibliotecas de uma instituição pública e reconhecida mundialmente. É com este impacto que destacamos que no momento atual as bibliotecas universitárias, como sempre fizeram e continuam, estão colaborando e participando ativamente da construção de textos e auxiliando para o crescimento da editoração científica e aumento da produção científica neste momento tão diferenciado.

Destacamos isto, justamente em relação a este ano pandêmico, e atípico que vivenciemos a partir de março de 2020, e provocou diversas mudanças no campo editorial e científico das publicações seriadas, despertando temáticas em diversas áreas do conhecimento sobre o COVID-19.

${ }^{1}$ Colaboração: Daniel Domingos da Rocha (Assistente Editorial da RDBCI) na coleta dos dados. 


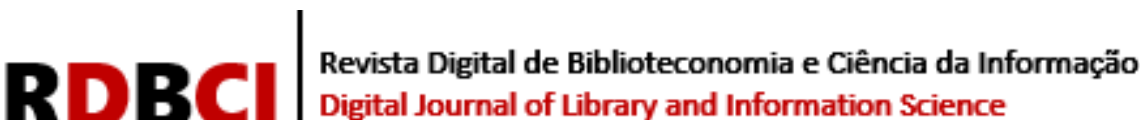

Até tínhamos pensando em oferecer um dossiê sobre o tema, mas vimos que outras publicações estavam realizar a mesma ação, e então, deixamos acontecer livremente e continuar recebendo os artigos em fluxo contínuo, e entre essas submissões, surgiu o recebimento de artigo sobre COVID-19 e bibliotecas universitárias, mas não falaremos agora sobre ele, mais a frente, falaremos sobre o objetivo e o propósito deste artigo submetido e aprovado na RDBCI.

Sendo assim, digamos que não escapamos, e não ficamos de fora de produzir trabalhos sobre o impacto do COVID-19 nas bibliotecas, que mostra a potência deste vírus em todas as áreas e devasta o mundo, mas, que em breve teremos a oportunidade de estarmos voltando à normalidade, haja visto que a vacina já está sendo recebida em diversos continentes para nossa esperança.

As mudanças de paradigmas e rotinas afetaram em muito o mundo da comunidade científica que, teve que produzir muito mais do que anos anteriores, tentando produzir artigos originais e ao mesmo tempo elaborar estudos clínicos sobre a temática comentando anteriormente. Tudo isso mostrou-nos a nossa capacidade de produzir estudos e artigos atualizadíssimos, mesmo vivendo isolados, ou trabalhando em home office, com trabalhos de teor e qualidade de mesma intensidade dos artigos estrangeiros.

Nesta edição de publicação contínua da RDBCI em que tivemos 39 trabalhos publicados entre artigos, artigos de pesquisa, relatos, resenha, conseguimos fechar com trabalhos excelentes, que contou com o tempo hábil dos avaliadores que conseguiram cumprir a entrega de suas avaliações, não deixando a revista atrasar no recebimento dos originais revisados, e encaminhados para os autores no processo do fluxo editorial em tempo aceitável. Alguns avaliadores não conseguiram colaborar pelo incansável aumento de trabalho que tiveram durante a pandemia, e isso podemos compartilhar com vocês nossos leitores, pois foi a realidade de muitos profissionais da academia, impossibilitando sua colaboração para com a RDBCI.

Mesmo assim, com o esforço feito pelos avaliadores, conseguirmos publicar tivemos 30 artigos originais; 7 artigos de pesquisa; 1 relato de experiência e 1 resenha. Este foi nosso saldo para fechar 2020, tendo em vistas que outros trabalhos estão em processo de avaliação, mas infelizmente entrarão se forem aprovados, na $19^{\mathrm{a}}$ edição desta prestigiada Revista. A temática foi diversificada, falando de mediação, bibliotecas universitárias, bibliometria, preservação digital, acervos e patrimônios arquivísticos, gestão da informação e outros. Desta forma, isto possibilitou-nos a criar uma titulação para esta edição, denominada: "Tópicos e diversidade temática na Biblioteconomia e Ciência da Informação".

Além disso, tivemos como destaque na edição de 2020, as palavras-chave mais procuradas, tais como "Ciência da Informação; Biblioteconomia; Bibliometria; Gestão da Informação; Bibliotecários; Arquivologia; Bibliotecas escolares e Inovação". Com todo esse destaque das palavras destacadas nas nuvens de palavras e pesquisadas na revista a palavras-chave que mais se destacou nestas buscas foi: "Inovação", e isso tem tudo a ver com o que estamos passando e tentando resolver problemas. Houve grande procuram sobre o tema, e uma busca de solução para criar e inovar produtos e serviços no âmbito das bibliotecas universitárias e da editoração científica. 


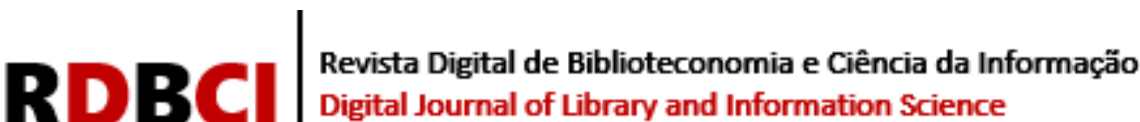

E por falar em inovação, a RDBCI a partir da edição e artigos submetidos para compor o volume da publicação contínua de 2021, passara adotar a modalidade CRediT $^{\mathbf{2}}$. Esse acrônimo que significa "Taxonomia de Funções de Contribuidor" é uma taxonomia de alto nível, incluindo 14 funções, que pode ser usada para representar as funções normalmente desempenhadas por contribuidores para a produção científica acadêmica. As funções descrevem a contribuição específica de cada colaborador para a produção acadêmica. Assim adotaremos nos próximos trabalhos identificando a autoria de cada participante da produção científica aprovada na RDBCI.

Por último, informamos que a Comissão Editorial decidiu flexibilizar a composição de autores no artigo, tendo em vista a aplicação do CRediT, passando de três (3) autores para até cinco (5) autores no trabalho. Outro item é sobre a Política de Quarentena, passando de dezoito (18) meses para apenas um (1) ano de submissão, quando submeter um novo trabalho à revista.

Vamos abrir a seção Artigos, com a contribuição intitulada: "O papel do bibliotecário como mediador da informação na busca pelo letramento informacional", de autoria de Kelly Rita de Azevedo e Mardochée Ogécime (ambas da Universidade Federal de Minas Gerais) discute sobre o papel do bibliotecário como mediador da informação na busca pelo letramento informacional, focando-se em um melhor atendimento às necessidades do usuário, levando em consideração seu contexto sociocultural frente às novas demandas e dinâmicas informacionais. De uma revisão sistemática acerca da temática, as autoras empreendem-se a dimensão teórico-analítica da mesma instituindo-se um traçado sobre algumas teorias interdisciplinares para a compreensão das possíveis mediações que envolvem as aproximações sucessivas desse objeto de estudo.

No segundo artigo "Divulgar, solicitar e restringir: os verbos conjugados no acesso à informação pública nos países do Cone Sul", de autoria de Thiago Gomes Eirão e Fernando César Lima Leite (ambos da Universidade de Brasília), os autores tratam do estudo do acesso à informação pública no contexto dos países do Cone Sul. A partir do estudo das leis que disciplinam a questão em cinco países do Cone Sul: Argentina, Brasil, Chile, Paraguai e Uruguai, o presente trabalho investiga as características e a consonância dos textos legais com as diretrizes teóricas de acesso à informação pública preconizadas por Braman, Mendel e o Modelo Interamericano de Lei de Acesso à Informação.

Em “Cenários prospectivos: revisão sistemática na Lisa, Emerald, Scopus e Web of Science", Adelaide Helena Targino Casimiro e Wagner Junqueira Araújo (ambos da Universidade Federal da Paraíba), tiveram como objetivo neste estudo, identificar nas bases Emerald, Lisa, Scopus e Web of Science os documentos que discorrem sobre o tema "cenários prospectivos" e caracterizá-los quanto às palavras-chave, periódicos e autorias. Os resultados indicaram que os textos identificados podem ser utilizados como referência por empresas e/ou organizações de Estado, desde que com as devidas adaptações às realidades encontradas.

Milton Shintaku e Ingrid Torres Schiessl (ambos do Instituto Brasileiro de Informação em Ciência e Tecnologia) no artigo "O conhecimento sobre o software Koha no

${ }^{2}$ Disponível em: CRediT - Contributor Roles Taxonomy - https://casrai.org/credit/. 


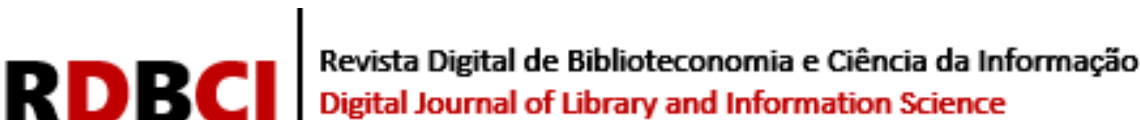

Brasil pelos professores de Biblioteconomia de cursos presenciais", os autores tem por objetivo analisar o grau de conhecimento sobre o software Koha pelos docentes do curso de graduação em Biblioteconomia no Brasil. Para tanto, utilizou-se a técnica do survey, por meio de questionário eletrônico, enviado a docentes dos cursos de biblioteconomia em todo o país. O estudo confirmou a hipótese levantada, de forma a possibilitar a criação de estratégias para a disseminação desse software aos professores.

No artigo seguinte sobre "A indexação de assunto em documentos arquivísticos: análise das definições internacionais com base na revisão sistemática da literatura", Graziela Martins de Medeiros e Marisa Braschër Basilio Medeiros (ambas da Universidade Federal de Santa Catarina), as autoras enfatizam os aspectos terminológicos e conceituais da indexação de assunto em documentos arquivísticos. Identificam as definições apresentadas na literatura científica nacional e internacional e verificam o entendimento de assunto e de conteúdo no âmbito desse processo, tornado possível indicar seus elementos constitutivos. A pesquisa, de caráter exploratório-descritivo e de natureza qualitativa, utiliza a revisão sistemática da literatura.

"Belarmino de Mattos: o Didot da imprensa maranhense no império", trabalho de autoria de Cesar Augusto Castro e Amaury Araujo Santos (ambos da Universidade Federal do Maranhão), discorre sobre a trajetória pessoal e profissional de Berlarmino de Mattos, tipográfo que atuou na Província do Maranhão no oitocentos e face a qualidade dos seus impressos - livros, jornais, folhetos, etc - recebeu o codinome de Didot maranhense. Os autores consideram que esta pesquisa traz importantes e férteis contribuições para a História da Imprensa, do Livro e da Leitura no Brasil.

Fernanda Vasconcelos Amaral e Elisa Cristina Delfini Corrêa (ambas da Universidade do Estado de Santa Catarina) publicaram o trabalho sobre as "Contribuições da Biblioteconomia e Ciência da Informação para a gestão de bibliotecas universitárias". As autoras perceberam que, atualmente, a Biblioteconomia está mais centrada em questões relacionadas com responsabilidade social e democratização da educação, enquanto a Ciência da Informação foca seus esforços em pesquisas relacionadas à compreensão da informação enquanto fenômeno em diferentes contextos. Dentre estes, interessa a este artigo, a informação estratégica e profissional, dentro de organizações. Entre esses dois enfoques, está a biblioteca universitária, que ocupa um papel de destaque tanto na área da educação como na de planejamento estratégico de um país. Por isso, o propósito deste artigo é analisar as contribuições dos dois campos para a gestão de bibliotecas universitárias na atualidade e questões relacionadas a instabilidade da sociedade, que demanda constantes redefinições dos serviços prestados.

No artigo sobre a "Informação social e cultura informacional: uma análise fílmica da obra 'O menino que descobriu o vento", de autoria de Viviane Holanda Cabral, Luiz Tadeu Feitosa e Lídia Eugenia Cavalcante (todos da Universidade Federal do Ceará), eles buscam refletir sobre as teorias relacionadas ao conceito de informação social e cultura informacional, ou seja, produção/construção, comunicação/veiculação e consumo/apropriação, à luz de análise fílmica da narrativa, baseada em uma história real, cujo enredo chegou ao cinema com o título "O menino que descobriu o vento". Assim, os autores tem como objetivo nos apresentar a compreensão do papel da biblioteca como geradora de transformação social, a partir da participação do bibliotecário/mediador como integrante do processo de mediação da informação e construção do conhecimento. Eles 


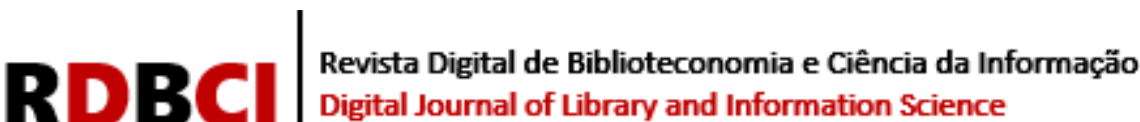

concluem que o quão relevante é o poder da informação social construída por meio do acesso ao conhecimento.

"A disseminação da informação científica como garantia da legitimidade dos resultados de ensaios clínicos" dos autores Larissa Ferreira dos Angelos Cedro e Cláudio Gottschalg-Duque (ambos da Universidade de Brasília), tem como objetivo de identificar na literatura as publicações que retratam a necessidade de disseminação dos resultados de ensaios clínicos como critério de transparência e validação destes. De forma integrada foi estabelecida a relação da Ciência da Informação como a área que se dedica ao compartilhamento da informação através da organização, comunicação e divulgação científica.

Danilo Camargo Dias, Walter Moreira e Rachel Cristina Vesu Alves (todos da Universidade Estadual Paulista), contribuíram com o artigo sobre "A representação temática de imagens digitais da NASA no Flickr: as contribuições dos sistemas de organização do conhecimento". Novamente os autores trouxeram a Ciência da Informação como um objeto do artigo, objetivando a analisar as contribuições do Sistema de Organização do Conhecimento - SOC - da National Aeronautics and Space Administration - NASA, na representação temática de imagens digitais disponibilizadas em redes sociais do Flickr. Como resultados da análise destaca-se os desafios gerados no uso da folksonomia na representação temática de imagens digitais e as vantagens do uso do SOC nos processos de representação temática e recuperação da informação nesses ambientes. Os autores concluíram que as folksonomias representam livremente os termos e refletem a realidade terminológica de uma comunidade; enquanto que os SOC contribuem para um controle de vocabulário e recuperação da informação mais precisa.

No âmbito do contexto sobre a preservação digital, Danilo Formenton e Luciana de Souza Gracioso (ambos da Universidade Federal de São Carlos), trouxeram o artigo: "Preservação digital: desafios, requisitos, estratégias e produção científica". Este artigo teve como objetivo a promoção de uma visão ampla e reflexiva dos principais aspectos da preservação digital, a partir dos desafios indicados, dos requisitos reconhecidos e das estratégias analisadas pela comunidade científica. Na produção científica internacional (2015-2019), o Brasil destaca-se pelas quantias de publicações indicando uma maduração do tema e pactuando com o avanço dos projetos nacionais, como a Rede Cariniana. Porém, temos demandas financeiras, humanas e tecnológicas que, unido às características das estratégias para preservação digital, expõem a utilidade das colaborações e dos tópicos nacionais pouco explorados.

No $12^{\circ}$ artigo, Marcos Felipe Gonçalves Maia (Universidade Federal do Tocantins) e Maria das Graças Gonçalves Vieira Guerram (Universidade Federal da Paraíba), com o trabalho intitulado: "Princípios avaliativos para biblioteca universitária: promovendo cultura, arte e conhecimento para além do acervo de livros", tratam da avaliação da biblioteca universitária no contexto do Sistema Nacional de Avaliação da Educação Superior (SINAES). Os autores tem como objetivo, propor um modelo de princípios avaliativos para a biblioteca universitária que ultrapasse a simples verificação e atualização de acervos. Os autores concluem reforçando esse modelo para que as bibliotecas universitárias sejam avaliadas como da melhor qualidade e não como simples depósitos de livros. 


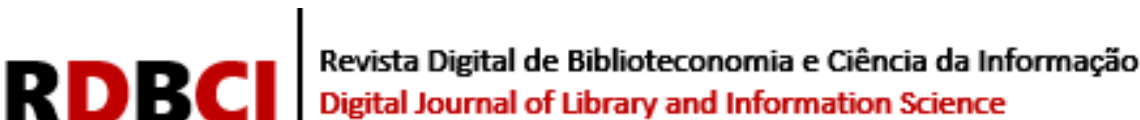

No artigo seguinte sobre as "Relações entre fluxo de informação e comportamento informacional de usuários em organizações formais: uma revisão sistemática de literatura", Wilimar Junio Ruas e Marcello Peixoto Bax (ambos da Universidade Federal de Minas Gerais), buscam identificar na literatura como se dão as relações entre fluxo de informação e comportamento informacional de usuários em organizações formais.

Em "Bibliometria e ciência de dados: um exemplo de busca e análise de dados da Web of Science (WoS)", Lena Lúcia de Moraes e Ivette Kafure (ambas da Universidade de Brasília), mostram por meio de deste estudo prático, como um estudante pode usar as técnicas e ferramentas da Bibliometria, Ciência de Dados, Ciência de Redes e Big Data para realizar o levantamento bibliográfico de pesquisas. Os resultados da análise das redes facilitaram a combinação de elementos para entendimento de informações e conhecimentos da área estudada. Assim, foi possível ter uma visão geral das áreas, bem como, a exploração de contextos específicos, facilitando e direcionando a delimitação da pesquisa, minimizando a ansiedade da informação.

Andreza Vellasco Gomes e Eduardo Romero de Oliveira (ambos da Universidade Estadual Paulista), trouxeram a contribuição: "Patrimônio documental e acervos: políticas públicas através da formação do acervo documental da Biblioteca do Museu da Companhia Paulista". Neste artigo, as autoras estudaram o acervo documental do Museu da Companhia Paulista em Jundiaí, visando identificar como se deu a formação do acervo documental a fim de contribuir para sua valoração e organização como patrimônio documental e ferroviário.

A morosidade judicial tem sido tema de debates na comunidade acadêmica brasileira. Entre as soluções discutidas, a jurimetria tem ganhado espaço ao buscar por padrões quantitativos nas decisões judiciais. Porém, em que pese a relevância desta metodologia, no Brasil, poucas pesquisas têm sido conduzidas no sentido de sua disseminação. Assim sendo, Marcos Maia e Cicero Aparecido Bezerra (ambos da Universidade Federal do Paraná) em "Análise bibliométrica dos artigos científicos de jurimetria publicados no Brasil", empregam técnicas de bibliometria sobre a produção científica nacional, relacionada ao termo "jurimetria", de 2002 até 2019, disponibilizada na base de dados Google Acadêmico, apresentando um painel informativo sobre as características (autor, citações, palavras-chave, revistas) encontradas nestas publicações.

No próximo artigo sobre a "Governança corporativa: levantamento da produção em artigos recuperados da Scopus", Marcelo Maia e Denise Fukumi Tsunoda (ambos da Universidade Federal do Paraná), investigam a produtividade dos pesquisadores quanto a temporalidade, quantidade de autores, aplicando a Lei de Lotka (utilizando o modelo do poder inverso generalizado para contagem direta e completa), utilizando como metodologia a pesquisa descritiva, com abordagem quantitativa, realizando uma análise bibliográfica da produção nacional e internacional em janeiro de 2020 por meio da base Scopus. Os resultados apontaram que o número de colaboradores cresceu continuamente nos últimos anos e que a configuração de dois e três autores vem tornando-se mais frequente.

Eliane Cristina de Freitas Rocha (Universidade Federal de Minas Gerais) no artigo sobre "As mediações como objeto de pesquisa em periódicos brasileiros da Ciência da Informação e áreas correlatas", procura apresentar como a temática das medições tem sido abordada na Ciência da Informação e Biblioteconomia e em áreas correlatas (Arquivologia, Museologia e Sistemas de Informação) em âmbito nacional. 
"Gestão de riscos: o método do COSO aplicado à gestão de uma unidade de informação", de autoria de Dulce Elizabeth Lima de Sousa e Silva (Instituto Federal de Educação Ciência e Tecnologia de Sergipe), Sérgio Luiz Elias de Araújo e Lorena de Oliveira Souza Campello (ambos da Universidade Federal de Sergipe), tem como objetivo apresentar os resultados obtidos na Coordenadoria Geral de Protocolo e Arquivo (CGPA), setor responsável pela Gestão Documental, referentes a aplicação do método elaborado pelo Committee of Sponsoring Organizations (COSO) - orientado no âmbito do Governo Federal por meio do manual de gestão de integridade, riscos e controles internos da gestão que vem sendo utilizado no Instituto Federal de Educação, Ciência e Tecnologia de Sergipe (IFS) pelo Departamento de Gestão de Riscos.

Simone Assis Alves da Silva e Ana Maria Pereira Cardoso (ambas da Universidade FUMEC), contribuem nesta edição de 2020, com o artigo "Literacia informacional: uma revisão sistemática de literatura". As autoras verificaram o atual cenário de pesquisa sobre a Literacia, tanto na perspectiva do tipo de abordagem- literacia digital ou literacia da informação- quanto às áreas do conhecimento em que se investiga o tema. As autoras concluíram que os estudos que se dedicaram à literacia da informação representam não somente uma demanda da atual sociedade, como também exprimem uma preocupação no desenvolvimento de ações que possam inserir o tema no âmbito da educação formativa e da aprendizagem para a vida em um contexto de avanços tecnológicos sem precedentes na história da humanidade.

Rubens da Silva Ferreira (Universidade Federal do Pará) em "A dimensão contemplativa do acesso à informação em uma coleção bibliográfica do século XIX: a biblioteca do Barão de Guajará", busca analisar a dimensão contemplativa do acesso à informação em uma coleção bibliográfica do século XIX: os livros da biblioteca do Barão de Guajará. Esta coleção atualmente pertence ao Instituto Histórico e Geográfico do Pará (IHGP) e adquiriu o status de objeto de exposição. Concluiu-se com este estudo, a percepção de uma experiência estética e sensível que remete o observador a Belém Imperial com os seus modos de consumir a cultura impressa que escova das editoras e livrarias da França.

Ao longo do tempo, a biblioteca escolar tem modificado o seu perfil, abrindo as portas para a mediação cultural ao tentar deixar para trás o estigma de lugar silencioso e cobrando uma nova atuação do bibliotecário escolar. Com isso, Hélio Márcio Pajeú e Arthur Henrique Feijó de Almeida (ambos da Universidade Federal de Pernambuco) no artigo "A mediação cultural na biblioteca escolar e o bibliotecário infoeducador", analisam o caminho trilhado pela biblioteca escolar no Brasil a fim de refletir sobre sua atual configuração como um espaço de mediação cultural e o papel do bibliotecário infoeducador no contexto atual desses espaços, por meio de uma pesquisa exploratória de caráter bibliográfico e documental e de uma revisão diacrônica do conceito de biblioteca escolar.

"Convergências entre a teoria da troca social e a mediação da informação e do conhecimento na perspectiva dos desenvolvedores de software: um estudo de caso", de autoria de Leonardo Pereira Pinheiro de Souza (Universidade Estadual), João Arlindo dos Santos Neto (Universidade Estadual de Londrina) e Cássia Regina Bassan de Moraes (Universidade Estadual Paulista), tem como objetivo verificar como se dá o compartilhamento de informação e conhecimento entre profissionais de software, inferindo como princípios da Teoria da Troca Social interferem ou em sua mediação, destacando a 


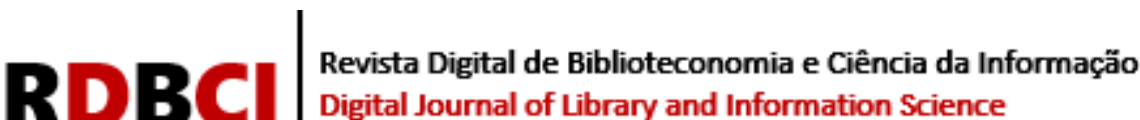

influência de motivadores egocêntricos e altruístas, ou voltados à coletividade. Os autores concluíram que existem convergências entre a Teoria da Troca Social e a mediação da informação, tanto no aspecto teórico quanto prático, evidenciando a possiblidade da mediação além dos equipamentos informacionais tradicionais: bibliotecas, arquivos e museus.

Novamente voltamos a falar do tema sobre "A preservação digital em longo prazo amparada por planos de ações: uma revisão sistemática de literatura", tendo como autoras Luciana Gonçalves Silva Souza e Elisângela Cristina Aganette (Universidade Federal de Minas Gerais). As autoras destacam neste artigo que um planejamento adequado das atividades de preservação inclui o desenvolvimento e institucionalização de uma política de preservação digital e a implementação das orientações estabelecidas por meio do plano de preservação digital, com a definição dos procedimentos relativos à manutenção e à preservação dos registros digitais por longo prazo. Por meio da construção deste artigo, elas buscam identificar estruturas e experiências de elaboração do plano de preservação digital. Para tanto, foram buscar como método neste levantamento, a revisão sistemática de literatura. Assim, notaram que a revisão evidenciou a reduzida exploração do termo plano de preservação digital e dos conteúdos a ele associados na literatura científica, aspecto que, possivelmente, indica a recente utilização do instrumento como orientador para o desenvolvimento das ações de preservação digital nas instituições.

No artigo sobre "A relação entre catalogação e o serviço de referência", Luiza Arias (Universidade Federal do Rio de Janeiro) e Naira Christofoletti Silveira (Universidade Federal do Estado do Rio de Janeiro), tiveram como objetivo revelar a relação entre o serviço de referência e o catálogo, através das tarefas do usuário dos Requisitos Funcionais para Registros Bibliográficos (FRBR) e das seis fases do processo de referência propostas por Nice Figueiredo.

No artigo seguinte sob o título "Commons de Conhecimento em Bibliotecas de Instituições de Ensino Superior em Curitiba (PR)", elaborado por Ana Paula da Silva Rodrigues (Prefeitura Municipal de Piraquara), Andressa Rando Favorito e Maria de Lourdes Alves Figueiredo (sendo estes dois últimos da Universidade Tecnológica Federal do Paraná), as autoras consideraram neste estudo o conhecimento como um bem comum, conforme proposta de Charlotte Hess e Elinor Ostrom. Assim o presente artigo tem por objetivo identificar a biblioteca universitária enquanto um commons de conhecimento. Elas indicaram nos resultados que o acervo digital da biblioteca pública se enquadra nos princípios de governança de commons de conhecimento, no que se refere as regras de governança, assim como a biblioteca da privada.

Conforme comentamos no início deste editorial, chegamos no artigo comentado referente ao COVID-19, onde as autoras e pesquisadores/docentes Rejane Sales de Lima Paula (Universidade Federal de Rondônia), Elaine da Silva (Universidade Federal de São Carlos) e Luana Maia Woida (Faculdade de Tecnologia de Garça), estudaram sobre " $\boldsymbol{A}$ inovação nas bibliotecas universitárias em tempo de pandemia da região norte do Brasil". $\mathrm{O}$ artigo identificado como pesquisa qualitativa de natureza básica utiliza o método exploratório e descritivo, com revisão bibliográfica referente à temática de inovação nas bibliotecas universitárias. As autoras destacam que o resultado de pesquisa foi coletado nos websites das bibliotecas da região norte do Brasil. O levantamento dos dados permitiu um melhor entendimento da forma como as bibliotecas universitárias da região do Brasil estão 


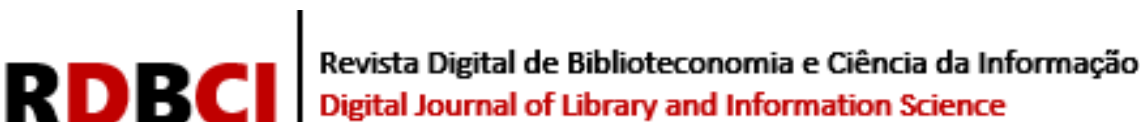

atendendo as necessidades informacionais de seus usuários no período de pandemia da COVID-19. Apesar de algumas das bibliotecas universitárias não estarem desenvolvendo ações voltadas para a capacitação de sua comunidade acadêmica, ainda há aquelas que vem apoiando as atividades acadêmicas através de atitudes inovadoras na sociedade contemporânea, como a oferta de serviços e produtos informacionais de forma diversificada.

Na contribuição sobre o "Pós-humanismo e pós-humano: revisão sistemática em bases científicas" de autoria de Adelaide Helena Targino Casimiro e Wagner Junqueira de Araújo (ambos da Universidade Federal da Paraíba), os autores tiveram como objetivo refletir sobre os conceitos relacionados ao tema "pós-humanismo" e suas abordagens pela Ciência da Informação (CI) e demais áreas da Ciência. Os resultados indicaram que estamos em um período histórico em que não é válido levantar questões sobre o que faremos quando as pessoas se tornarem pós-humanas, porque já vivenciamos esta realidade, e portanto, os estudos devem ser pautados naquilo que podemos fazer agora para atender aos padrões e exigências de consumo desses indivíduos.

Na temática sobre PCV, Cláudio Gonçalves Bernardo, Ivette Kafure Muñoz e Tiago Barros Pontes e Silva (todos da Universidade de Brasília) contribuíram com o artigo: "Pessoa com deficiência visual e a acessibilidade à informação para mobilidade indoor". Neste artigo, os autores apresentaram a proposta de desenvolvimento de artefato eletrônico, utilizando o sistema Dosvox que é amplamente utilizado por PDV, que lhe proporcione informação na sua mobilidade em qualquer espaço físico interno, posto que disponibiliza informações sobre distância, profundidade e lateralidade do ambiente, sendo categorizado como um mapa auditivo.

Resenhas e entrevistas publicadas em periódicos científicos têm recebido pouca atenção em pesquisas do campo da Ciência da Informação. Por esta razão, Maria Cristina Piumbato Innocentini Hayashi (Universidade Federal de São Carlos), no artigo sobre as "Evidências bibliométricas do reconhecimento científico em resenhas e entrevistas: notas teóricas e modelo de análise", defende a ideia de que a análise desses gêneros textuais pode evidenciar o reconhecimento científico quando são tomados como objetos de estudo a partir de uma perspectiva bibliométrica. Os objetivos foram realizar um ensaio teórico sobre resenhas e entrevistas e elaborar um modelo de análise desses gêneros textuais. O modelo de análise elaborado sinaliza o reconhecimento científico presente nas resenhas e entrevistas, e destaca a importância desses objetos de estudo para o campo da Ciência da Informação.

Na seção Artigos de Pesquisa, abrimos com o texto sobre "A implementação de coleções em repositórios institucionais: o caso da coleção cadernos UFS de geografia e história da Universidade Federal de Sergipe", de autoria de Carolina Karla Fernandes e Martha Suzana Cabral Nunes (ambas da Universidade Federal de Sergipe). O presente artigo apresentou parte dos resultados de uma pesquisa de mestrado profissional e teve como objetivos descrever e mapear as etapas da digitalização da coleção Cadernos UFS: Geografia/ História existentes no Setor de Periódicos da biblioteca Central da Universidade Federal de Sergipe (UFS) e a sua implementação no repositório institucional para domínio público.

Em “Comunicação entre sistemas de informação médicos: princípios para elaborar definições", Amanda Damasceno de Souza e Maurício Barcellos Almeida (ambos da Universidade Federal de Minas Gerais), apresentaram um método que estabelece princípios para sistematização do processo de criação de definições padronizadas, as quais possam para 


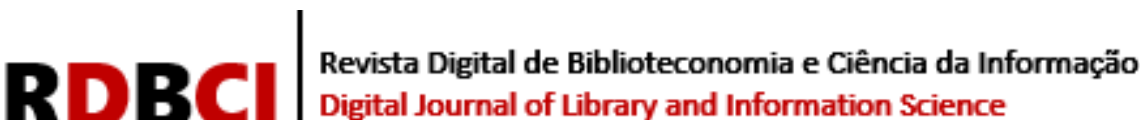

proporcionar a esperada comunicação entre sistema de informação médicos, e, portanto, melhor atendimento ao cidadão. Com isso, os autores esperam que essa experiência possa contribuir para a melhorias nos projetos em que a Ciência da Informação apoia a medicina e os cuidados à saúde na busca por melhor atendimento ao cidadão.

No terceiro trabalho desta seção sobre o "Uso do Portal de Periódicos da Capes por pesquisadores em um Programa de Pós-Graduação: um estudo de caso em uma Instituição Federal de Ensino Superior", Ricardo Coutinho Mello (Universidade Federal da Bahia) discute os fatores que influenciaram o uso do Portal de Periódicos da Coordenação de Aperfeiçoamento de Pessoal de Nível Superior pelo corpo docente de um Programa de PósGraduação na área das ciências sociais aplicadas da Universidade Federal da Bahia, identificando a fase atual do processo de institucionalização do uso da ferramenta, como instrumento de acesso à informação.

No artigo seguinte intitulado: "Avaliação do uso do twitter no sistema de bibliotecas da Universidade Federal de Sergipe: estratégias de marketing digital", de autoria de Valdiceia de Jesus Cardoso Pinheiro, Pablo Boaventura Sales Paixão e Cristina de Almeida Valença Cunha Barroso (todo da Universidade Federal de Sergipe), teve como objetivo analisar a utilização do twitter do Sistema de Bibliotecas da Universidade Federal de Sergipe (SIBIUFS) como estratégia de marketing digital.

Roberta Cristina Dal'Evedove Tartarotti (Universidade Estadual de Campinas) no seu trabalho sobre a "Representação temática em repositórios institucionais de bibliotecas universitárias a percepção de gestores e bibliotecários catalogadores-indexadores da USP, UNESP e UNICAMP", teve como objetivo investigar a representação temática da informação documental em repositórios institucionais no contexto de bibliotecas universitárias, por meio de entrevista semiestruturada de diagnóstico organizacional com gestores e bibliotecários catalogadores-indexadores dos repositórios institucionais da USP, UNESP e UNICAMP, com coleta de documentação.

"Modelo baseado em Frictionless Data aplicado aos dados abertos governamentais" é o artigo de pesquisa de autoria de Melissa Figueira Fagundes e Divino Ignácio Ribeiro Junior (ambos da Universidade do Estado de Santa Catarina). O presente trabalho propõe um modelo baseado em Fricitionless Data (FD) para auxiliar na publicação de dados abertos governamentais (DAGs). O estudo procurou contribuir ao aplicar o modelo ao conjunto de dados com informações sobre as boas práticas executadas pelo Judiciário relacionadas aos Objetivos de Desenvolvimento Sustentável (ODS). O modelo se baseou no Data Publication Workflow, um fluxo para publicação de dados disponível no site da iniciativa Frictionless Data e que aborda etapas como empacotamento, tratamento e publicação dos dados.

No último trabalho desta seção os "Indicadores de acoplamento bibliográfico para a avaliação da proximidade teórico-metodológica em redes de genealogia acadêmica: um estudo aplicado aos descendentes bolsistas PQ de Aldo Barreto", Rafael Gutierres Castanha, e Maria Cláudia Cabrini Grácio (ambos da Universidade Estadual Paulista), analisam a contribuição do Método de Acoplamento Bibliográfico para a avaliação da intensidade da transmissão da corrente teórico-metodológica de um pesquisador entre seus descendentes acadêmicos. Como universo de análise, o estudo utiliza o conjunto de doutores bolsistas PQ orientados por Aldo Barreto, pesquisador PQ Sênior da área de Ciência da Informação. 


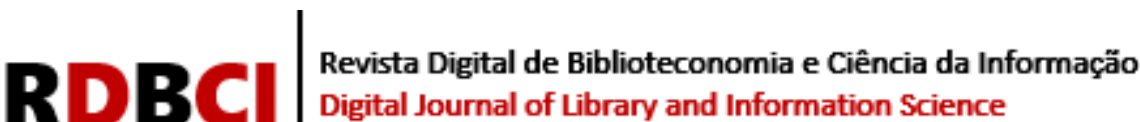

Observou-se a constância da influência de Pierre Bourdieu e Michel Foucault na rede de genealogia acadêmica analisada. Os autores consideraram que o Acoplamento Bibliográfico de Autores contribuiu para a análise da intensidade da transmissão da identidade científica na linhagem genealógica do grupo de pesquisadores estudados.

Na seção Relato de Experiência, tivemos a contribuição de Maria das Graças Targino (Universidade Federal da Paraíba), com a trabalho: "Universidades são o retrato educacional das nações, bibliotecas são o retrato das universidades: relato de experiência da Biblioteca Central da Universidade Federal do Piauı’'. O relato de experiência consiste em texto que descreve as ações pioneiras do sistema de bibliotecas universitárias do Estado do Piauí (PI), a partir da instalação da primeira universidade pública federal, Universidade Federal do Piauí (UFPI), instituída em 21 de novembro de 1968, com a fusão das faculdades isoladas de Medicina, Odontologia, Filosofia, Direito e Administração e suas respectivas coleções bibliográficas, iniciando as atividades em janeiro de 1973, Campus Universitário Petrônio Portela, Teresina - PI.

Finalizamos com a seção Resenha, com o trabalho "O bibliotecário sábio", resenhada por Gildenir Carolino Santos (Universidade Estadual de Campinas). Apresenta a resenha do livro "A sabedoria do bibliotecário", escrito por Michel Melot, que foi traduzido do francês (La sagesse du bibliothécaire) pelas editoras Ateliê Editorial e Edições SESC. A temática do livro está focada na bibliofilia, bibliotecários e a Biblioteconomia como profissão. Uma obra publicada com a primeira edição brasileira em 2020.

Esperamos que esta edição possa contribuir muito com a temática apresentada, e também produzir frutos com novos artigos e citados em novos levantamentos. Como dissemos no início, tivemos e estamos atravessando um período ainda pandêmico, devido ao COVID-19, e, portanto, continuemos isolados fisicamente e produzindo textos e artigos de forma virtual.

Ao mesmo tempo que nos despedimos com este editorial, desejamos a todos um excelente 2021, como muita perseverança, conhecimento e compartilhamento de informação e saberes, isto nos fará continuar a atuar no que mais gostamos em fazer no contexto editorial e informacional.

\section{Referências}

Campinas, SP, dezembro/2020.

AMARAL, F. V.; CORRÊA, E. C. D. Contribuições da Biblioteconomia e Ciência da Informação para a gestão de bibliotecas universitárias. RDBCI: Revista Digital de Biblioteconomia e Ciência da Informação, Campinas, SP, v. 18, e020008, 2020. DOI: 10.20396/rdbci.v18i0.8659172. Disponível em: https://periodicos.sbu.unicamp.br/ojs/index.php/rdbci/article/view/8659172. Acesso em: 30 dez. 2020.

ARIAS, L.; SILVEIRA, N. C. A relação entre catalogação e o serviço de referência. RDBCI: Revista Digital de Biblioteconomia e Ciência da Informação, Campinas, SP, v. 18, e020029, 2020. DOI: 10.20396/rdbci.v18i00.8661164. Disponível em: https://periodicos.sbu.unicamp.br/ojs/index.php/rdbci/article/view/8661164. Acesso em: 30 dez. 2020. 


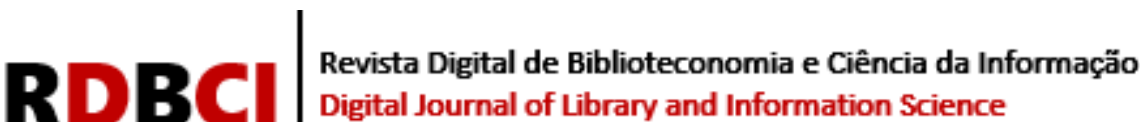

AZEVEDO, K. R. de; OGÉCIME, M. O papel do bibliotecário como mediador da informação na busca pelo letramento informacional. RDBCI: Revista Digital de Biblioteconomia e Ciência da Informação, Campinas, SP, v. 18, e020001, 2019. DOI: 10.20396/rdbci.v18i0.8654473. Disponível em: https://periodicos.sbu.unicamp.br/ojs/index.php/rdbci/article/view/8654473. Acesso em: 30 dez. 2020.

BERNARDO, C. G.; KAFURE MUÑOZ, I.; SILVA, T. B. P. e. Pessoa com deficiência visual e a acessibilidade à informação para mobilidade indoor. RDBCI: Revista Digital de Biblioteconomia e Ciência da Informação, Campinas, SP, v. 18, e020036, 2020. DOI: 10.20396/rdbci.v18i00.8661391. Disponível em: https://periodicos.sbu.unicamp.br/ojs/index.php/rdbci/article/view/8661391. Acesso em: 30 dez. 2020.

CABRAL, V. H.; FEITOSA, L. T.; CAVALCANTE, L. E. Informação social e cultura informacional : uma análise fílmica da obra "O menino que descobriu o vento". RDBCI: Revista Digital de Biblioteconomia e Ciência da Informação, Campinas, SP, v. 18, e020009, 2020. DOI: 10.20396/rdbci.v18i0.8658838. Disponível em:

https://periodicos.sbu.unicamp.br/ojs/index.php/rdbci/article/view/8658838. Acesso em: 30 dez. 2020.

CASIMIRO, A. H. T.; ARAÚJO, W. J. Cenários prospectivos: revisão sistemática na Lisa, Emerald, Scopus e Web of Science. RDBCI: Revista Digital de Biblioteconomia e Ciência da Informação, Campinas, SP, v. 18, e020003, 2020. DOI: 10.20396/rdbci.v18i0.8656945. Disponível em: https://periodicos.sbu.unicamp.br/ojs/index.php/rdbci/article/view/8656945. Acesso em: 30 dez. 2020.

CASIMIRO, A. H. T.; ARAÚJO, W. J. de. Pós-humanismo e pós-humano: revisão sistemática em bases científicas. RDBCI: Revista Digital de Biblioteconomia e Ciência da Informação, Campinas, SP, v. 18, e020033, 2020. DOI: 10.20396/rdbci.v18i00.8661569. Disponível em: https://periodicos.sbu.unicamp.br/ojs/index.php/rdbci/article/view/8661569. Acesso em: 30 dez. 2020.

CASRAI. CRediT - Contributor Roles Taxonomy. Disponível em: https://casrai.org/credit/. Acesso em: 30 dez. 2020.

CASTANHA, R. G.; GRÁCIO, M. C. C. Indicadores de acoplamento bibliográfico para a avaliação da proximidade teórico-metodológica em redes de genealogia acadêmica : um estudo aplicado aos descendentes bolsistas PQ de Aldo Barreto. RDBCI: Revista Digital de Biblioteconomia e Ciência da Informação, Campinas, SP, v. 18, e020039, 2020. DOI: 10.20396/rdbci.v18i00.8661393. Disponível em: https://periodicos.sbu.unicamp.br/ojs/index.php/rdbci/article/view/8661393. Acesso em: 30 dez. 2020.

CASTRO, C. A.; SANTOS, A. A. Belarmino de Mattos: o Didot da imprensa maranhense no império. RDBCI: Revista Digital de Biblioteconomia e Ciência da Informação, Campinas, SP, v. 18, e020007, 2020. DOI: 10.20396/rdbci.v18i0.8658261. Disponível em: 


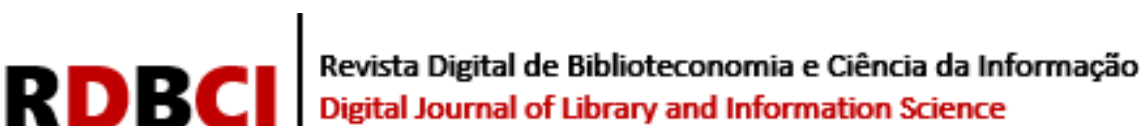

https://periodicos.sbu.unicamp.br/ojs/index.php/rdbci/article/view/8658261. Acesso em: 30 dez. 2020.

CEDRO, L. F. dos A.; GOTTSCHALG-DUQUE, C. A disseminação da informação científica como garantia da legitimidade dos resultados de ensaios clínicos. RDBCI: Revista Digital de Biblioteconomia e Ciência da Informação, Campinas, SP, v. 18, e020010, 2020. DOI: 10.20396/rdbci.v18i0.8658279. Disponível em: https://periodicos.sbu.unicamp.br/ojs/index.php/rdbci/article/view/8658279. Acesso em: 30 dez. 2020.

DIAS, D. C.; MOREIRA, W.; ALVES, R. C. V. A representação temática de imagens digitais da NASA no Flickr: as contribuições dos sistemas de organização do conhecimento. RDBCI: Revista Digital de Biblioteconomia e Ciência da Informação, Campinas, SP, v. 18, e020011, 2020. DOI: 10.20396/rdbci.v18i0.8658560. Disponível em: https://periodicos.sbu.unicamp.br/ojs/index.php/rdbci/article/view/8658560. Acesso em: 30 dez. 2020.

EIRÃO, T. G.; LEITE, F. C. L. Divulgar, solicitar e restringir: os verbos conjugados no acesso à informação pública nos países do Cone Sul. RDBCI: Revista Digital de Biblioteconomia e Ciência da Informação, Campinas, SP, v. 18, n. 00, p. e020002, 2020. DOI: 10.20396/rdbci.v18i0.8655940. Disponível em: https://periodicos.sbu.unicamp.br/ojs/index.php/rdbci/article/view/8655940. Acesso em: 30 dez. 2020.

FAGUNDES, M. F.; RIBEIRO JUNIOR, D. I. Modelo baseado em Frictionless Data aplicado aos dados abertos governamentais. RDBCI: Revista Digital de Biblioteconomia e Ciência da Informação, Campinas, SP, v. 18, e020034, 2020. DOI:

10.20396/rdbci.v18i00.8661528. Disponível em: https://periodicos.sbu.unicamp.br/ojs/index.php/rdbci/article/view/8661528. Acesso em: 30 dez. 2020.

FERNANDES, C. K.; NUNES, M. S. C. A implementação de coleções em repositórios institucionais: o caso da coleção cadernos UFS de geografia e história da Universidade Federal de Sergipe. RDBCI: Revista Digital de Biblioteconomia e Ciência da Informação, Campinas, SP, v. 18, e020004, 2020. DOI: 10.20396/rdbci.v18i0.8656366. Disponível em: https://periodicos.sbu.unicamp.br/ojs/index.php/rdbci/article/view/8656366. Acesso em: 30 dez. 2020.

FERREIRA, R. da S. A dimensão contemplativa do acesso à informação em uma coleção bibliográfica do século XIX: a biblioteca do Barão de Guajará. RDBCI: Revista Digital de Biblioteconomia e Ciência da Informação, Campinas, SP, v. 18, e020024, 2020. DOI: 10.20396/rdbci.v18i0.8660790. Disponível em: https://periodicos.sbu.unicamp.br/ojs/index.php/rdbci/article/view/8660790. Acesso em: 30 dez. 2020.

FORMENTON, D.; GRACIOSO, L. de S. Preservação digital: desafios, requisitos, estratégias e produção científica. RDBCI: Revista Digital de Biblioteconomia e Ciência da Informação, Campinas, SP, v. 18, e020012, 2020. DOI: 10.20396/rdbci.v18i0.8659259. 


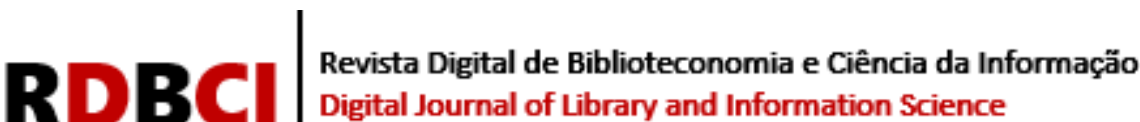

Disponível em: https://periodicos.sbu.unicamp.br/ojs/index.php/rdbci/article/view/8659259. Acesso em: 30 dez. 2020.

GOMES, A. V.; OLIVEIRA, E. R. de. Patrimônio documental e acervos: políticas públicas através da formação do acervo documental da Biblioteca do Museu da Companhia Paulista. RDBCI: Revista Digital de Biblioteconomia e Ciência da Informação, Campinas, SP, v. 18, e020017, 2020. DOI: 10.20396/rdbci.v18i0.8659250. Disponível em:

https://periodicos.sbu.unicamp.br/ojs/index.php/rdbci/article/view/8659250. Acesso em: 30 dez. 2020.

HAYASHI, M. C. P. I. Evidências bibliométricas do reconhecimento científico em resenhas e entrevistas: notas teóricas e modelo de análise. RDBCI: Revista Digital de

Biblioteconomia e Ciência da Informação, Campinas, SP, v. 18, e020037, 2020. DOI:

10.20396/rdbci.v18i00.8660743. Disponível em:

https://periodicos.sbu.unicamp.br/ojs/index.php/rdbci/article/view/8660743. Acesso em: 30 dez. 2020.

MAIA, M. F. G.; GUERRA, M. das G. G. V. Princípios avaliativos para biblioteca universitária: promovendo cultura, arte e conhecimento para além do acervo de livros. RDBCI: Revista Digital de Biblioteconomia e Ciência da Informação, Campinas, SP, v. 18, e020013, 2020. DOI: 10.20396/rdbci.v18i0.8659641. Disponível em:

https://periodicos.sbu.unicamp.br/ojs/index.php/rdbci/article/view/8659641. Acesso em: 30 dez. 2020.

MAIA, M.; BEZERRA, C. A. Análise bibliométrica dos artigos científicos de jurimetria publicados no Brasil. RDBCI: Revista Digital de Biblioteconomia e Ciência da Informação, Campinas, SP, v. 18, e020018, 2020. DOI: 10.20396/rdbci.v18i0.8658889. Disponível em: https://periodicos.sbu.unicamp.br/ojs/index.php/rdbci/article/view/8658889. Acesso em: 30 dez. 2020.

MAIA, M.; TSUNODA, D. F. Governança corporativa: levantamento da produção em artigos recuperados da Scopus. RDBCI: Revista Digital de Biblioteconomia e Ciência da Informação, Campinas, SP, v. 18, e020019, 2020. DOI: 10.20396/rdbci.v19i0.8658213. Disponível em: https://periodicos.sbu.unicamp.br/ojs/index.php/rdbci/article/view/8658213. Acesso em: 30 dez. 2020.

MEDEIROS, G. M. de; MEDEIROS, M. B. B. A indexação de assunto em documentos arquivísticos: análise das definições internacionais com base na revisão sistemática da literatura. RDBCI: Revista Digital de Biblioteconomia e Ciência da Informação, Campinas, SP, v. 18, e020006, 2020. DOI: 10.20396/rdbci.v18i0.8657824. Disponível em: https://periodicos.sbu.unicamp.br/ojs/index.php/rdbci/article/view/8657824. Acesso em: 30 dez. 2020.

MELLO, R. C. Uso do Portal de Periódicos da Capes por pesquisadores em um Programa de Pós-Graduação: um estudo de caso em uma Instituição Federal de Ensino Superior.

RDBCI: Revista Digital de Biblioteconomia e Ciência da Informação, Campinas, SP, v. 18, e020022, 2020. DOI: 10.20396/rdbci.v18i0.8660221. Disponível em: https://periodicos.sbu.unicamp.br/ojs/index.php/rdbci/article/view/8660221. Acesso em: 30 dez. 2020. 


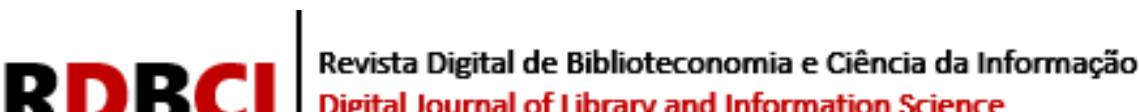 \\ Digital Journal of Library and Information Science}

MORAES, L. L. de; KAFURE, I. Bibliometria e ciência de dados: um exemplo de busca e análise de dados da Web of Science (WoS). RDBCI: Revista Digital de Biblioteconomia e Ciência da Informação, Campinas, SP, v. 18, e020016, 2020. DOI:

10.20396/rdbci.v19i0.8658521. Disponível em:

https://periodicos.sbu.unicamp.br/ojs/index.php/rdbci/article/view/8658521. Acesso em: 30 dez. 2020.

PAJEÚ , H. M.; ALMEIDA, A. H. F. de. A mediação cultural na biblioteca escolar e o bibliotecário infoeducador. RDBCI: Revista Digital de Biblioteconomia e Ciência da Informação, Campinas, SP, v. 18, e020025, 2020. DOI: 10.20396/rdbci.v18i0.8660541. Disponível em: https://periodicos.sbu.unicamp.br/ojs/index.php/rdbci/article/view/8660541. Acesso em: 30 dez. 2020.

PAULA, R. S. de L.; SILVA, E. da; WOIDA, L. M. A inovação nas bibliotecas universitárias em tempo de pandemia da região norte do Brasil. RDBCI: Revista Digital de Biblioteconomia e Ciência da Informação, Campinas, SP, v. 18, e020032, 2020. DOI: 10.20396/rdbci.v18i00.8661184. Disponível em: https://periodicos.sbu.unicamp.br/ojs/index.php/rdbci/article/view/8661184. Acesso em: 30 dez. 2020.

PINHEIRO, V. de J. C.; PAIXÃO, P. B. S.; BARROSO, C. de A. V. C. Avaliação do uso do twitter no sistema de bibliotecas da Universidade Federal de Sergipe: estratégias de marketing digital. RDBCI: Revista Digital de Biblioteconomia e Ciência da Informação, Campinas, SP, v. 18, e020028, 2020. DOI: 10.20396/rdbci.v18i0.8661193. Disponível em: https://periodicos.sbu.unicamp.br/ojs/index.php/rdbci/article/view/8661193. Acesso em: 30 dez. 2020.

ROCHA, E. C. de F. As mediações como objeto de pesquisa em periódicos brasileiros da Ciência da Informação e áreas correlatas. RDBCI: Revista Digital de Biblioteconomia e Ciência da Informação, Campinas, SP, v. 18, e02020, 2020. DOI:

10.20396/rdbci.v18i0.8659245. Disponível em:

https://periodicos.sbu.unicamp.br/ojs/index.php/rdbci/article/view/8659245. Acesso em: 30 dez. 2020.

RODRIGUES, A. P. da S.; FAVORITO, A. R.; FIGUEIREDO, M. de L. A. Commons de Conhecimento em Bibliotecas de Instituições de Ensino Superior em Curitiba (PR).

RDBCI: Revista Digital de Biblioteconomia e Ciência da Informação, Campinas, SP, v. 18, e020031, 2020. DOI: 10.20396/rdbci.v18i.8661538. Disponível em:

https://periodicos.sbu.unicamp.br/ojs/index.php/rdbci/article/view/8661538. Acesso em: 30 dez. 2020.

RUAS, W. J.; BAX, M. P. Relações entre fluxo de informação e comportamento informacional de usuários em organizações formais: uma revisão sistemática de literatura. RDBCI: Revista Digital de Biblioteconomia e Ciência da Informação, Campinas, SP, v. 18, e020014, 2020. DOI: 10.20396/rdbci.v18i0.8657980. Disponível em: https://periodicos.sbu.unicamp.br/ojs/index.php/rdbci/article/view/8657980. Acesso em: 30 dez. 2020. 


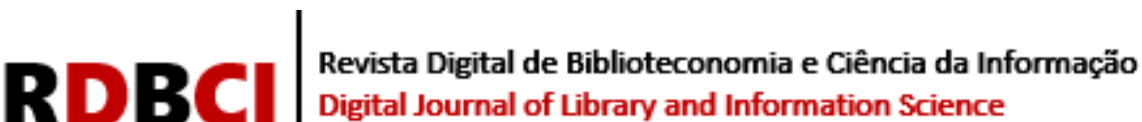

SANTOS, G. C. O bibliotecário sábio. RDBCI: Revista Digital de Biblioteconomia e Ciência da Informação, Campinas, SP, v. 18, p. e020038, 2020. DOI:

10.20396/rdbci.v18i00.8663466. Disponível em:

https://periodicos.sbu.unicamp.br/ojs/index.php/rdbci/article/view/8663466. Acesso em: 30 dez. 2020.

SHINTAKU, M.; SCHIESSL, I. T. O conhecimento sobre o software Koha no Brasil pelos professores de Biblioteconomia de cursos presenciais. RDBCI: Revista Digital de Biblioteconomia e Ciência da Informação, Campinas, SP, v. 18, e020005, 2020. DOI: 10.20396/rdbci.v18i0.8656058. Disponível em: https://periodicos.sbu.unicamp.br/ojs/index.php/rdbci/article/view/8656058. Acesso em: 30 dez. 2020.

SILVA, D. E. L. de S. e; ARAÚJO, S. L. E. de.; CAMPELLO, . L. de O. S. Gestão de riscos: o método do COSO aplicado à gestão de uma unidade de informação. RDBCI: Revista Digital de Biblioteconomia e Ciência da Informação, Campinas, SP, v. 18, e020021, 2020. DOI: 10.20396/rdbci.v19i0.8660794. Disponível em: https://periodicos.sbu.unicamp.br/ojs/index.php/rdbci/article/view/8660794. Acesso em: 30 dez. 2020.

SILVA, S. A. A. da; CARDOSO, A. M. P. Literacia informacional: uma revisão sistemática de literatura. RDBCI: Revista Digital de Biblioteconomia e Ciência da Informação, Campinas, SP, v. 18, e020023, 2020. DOI: 10.20396/rdbci.v18i0.8660680. Disponível em: https://periodicos.sbu.unicamp.br/ojs/index.php/rdbci/article/view/8660680. Acesso em: 30 dez. 2020.

SOUZA, A. D. de .; ALMEIDA, M. B. Comunicação entre sistemas de informação médicos: princípios para elaborar definições. RDBCI: Revista Digital de Biblioteconomia e Ciência da Informação, Campinas, SP, v. 18, e020015, 2020. DOI:

10.20396/rdbci.v18i0.8657089. Disponível em:

https://periodicos.sbu.unicamp.br/ojs/index.php/rdbci/article/view/8657089. Acesso em: 30 dez. 2020.

SOUZA, L. G. S.; AGANETTE, E. C. A preservação digital em longo prazo amparada por planos de ações: uma revisão sistemática de literatura. RDBCI: Revista Digital de Biblioteconomia e Ciência da Informação, Campinas, SP, v. 18, e020027, 2020. DOI: 10.20396/rdbci.v18i0.8661185. Disponível em: https://periodicos.sbu.unicamp.br/ojs/index.php/rdbci/article/view/8661185. Acesso em: 30 dez. 2020.

SOUZA, L. P. P. de; SANTOS NETO, J. A. dos; MORAES, C. R. B. de. Convergências entre a teoria da troca social e a mediação da informação e do conhecimento na perspectiva dos desenvolvedores de software: um estudo de caso. RDBCI: Revista Digital de Biblioteconomia e Ciência da Informação, Campinas, SP, v. 18, e020026, 2020. DOI: 10.20396/rdbci.v18i0.8661113. Disponível em: https://periodicos.sbu.unicamp.br/ojs/index.php/rdbci/article/view/8661113. Acesso em: 30 dez. 2020. 


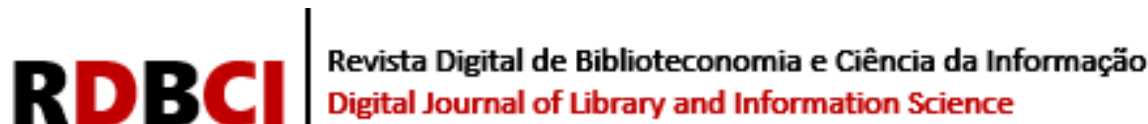

TARGINO, M. das G. Universidades são o retrato educacional das nações, bibliotecas são o retrato das universidades: relato de experiência da Biblioteca Central da Universidade Federal do Piauí. RDBCI: Revista Digital de Biblioteconomia e Ciência da Informação, Campinas, SP, v. 18, e020035, 2020. DOI: 10.20396/rdbci.v18i00.8661591. Disponível em: https://periodicos.sbu.unicamp.br/ojs/index.php/rdbci/article/view/8661591. Acesso em: 30 dez. 2020.

TARTAROTTI, R. C. D. Representação temática em repositórios institucionais de bibliotecas universitárias: a percepção de gestores e bibliotecários catalogadoresindexadores da USP, UNESP e UNICAMP. RDBCI: Revista Digital de Biblioteconomia e Ciência da Informação, Campinas, SP, v. 18, e020030, 2020. DOI:

10.20396/rdbci.v18i00.8660803. Disponível em: https://periodicos.sbu.unicamp.br/ojs/index.php/rdbci/article/view/8660803. Acesso em: 30 dez. 2020. 